\title{
ANALISIS PERBANDINGAN NILAI SAIDI(SYSTEM AVERAGE INTERRUPTION DURRATION INDEX) DAN SAIFI (SYSTEM AVERAGE INTERRUPTION FREQUENCY INDEX) PLN APJ PURWOKERTO TAHUN 2014, 2015 DAN 2016 DENGAN STANDAR SPLN 1985
}

\author{
Surya Nur Hidayat, Karnoto, dan Agung Warsito \\ Departemen Teknik Elektro, Universitas Diponegoro, Semarang \\ Jln. Prof. Sudharto, SH, Kampus UNDIP Tembalang, Semarang 50275, Indonesia \\ ${ }^{*}$ Email : suryanurhidayat@rocketmail.com
}

\begin{abstract}
Abstrak
SPLN 1985 merupakan standar yang ditetapkan pada tahun 1985, sudah lebih dari 30 tahun SPLN 1985 dipakai sebagai standar. Seiring dengan perkembangan jaman, SPLN 1985 yang digunakan masih sama seperti yang tahun 1985 sehingga perlu dilakukan penelitian kembali apakah standar SPLN 1985 masih sesuai dengan kondisi sekarang. Perbedaan infrastruktur, peralatan listrik dan jumlah pelanggan pada tahun 1985 dengan tahun-tahun sekarang ini tentunya terdapat perbedaan, hal tersebut memberikan pengaruh yang berbeda dengan nilai keandalan listrik seperti SAIDI dan SAIFI. Pada penelitian ini dilakukan pengkajian standar SPLN 1985 dengan data lapangan yang diperoleh dari PLN APJ Purwokerto tahun 2014, 2015 dan 2016 dengan membandingkan hasil perhitungan nilai SAIDI dan SAIFI data lapangan dengan standar SPLN 1985. Pada penelitian ini, dilakukan perhitungan nilai SAIDI dan SAIFI tahun 2014, 2015 dan 2016 kemudian dibandingkan dengan SPLN 1985. Dari perhitungan diketahui nilai SAIFI data lapangan tahun 2014 didapatkan hasil sebesar 11,47 kali/tahun, tahun 2015 sebesar 20,74 kali/tahun dan 2016 sebesar 20,36 kali/tahun sementara standar SAIFI SPLN sebesar 3,2 kali/tahun.. Nilai SAIDI data lapangan tahun 2014 sebesar 16,76 jam/tahun, tahun 2015 sebesar 30,28 jam/tahun dan tahun 2016 sebesar 35,16 jam/tahun sementara standar SPLN sebesar 21 jam/tahun.
\end{abstract}

Kata Kunci : SPLN 1985, SAIDI, SAIFI.

\begin{abstract}
SPLN 1985 is national electrical company standard which was applied in 1985, it has been used for over 30 years as national standard. When there are major improvements in equipment and technology in this era, SPLN 1985 is still used, therefore the re-examination is needed, the purpose is to know wether SPLN 1985 still relevant in the present condition or not. The condition in the past when SPLN firstly applied is different compared to the present. The differences are infrastructures, electrical equipments, and number of customer. These conditions give different effect to electrical reliability value, such as SAIDI and SAIFI. This research is aimed to re-examine SPLN 1985 with data from PLN APJ Purwokerto in 2014, 2015 and 2016. The result shows that there are differences in SAIDI and SAIFI. The result of SAIFI from actual data in 2014 is 11,47 time/year, in 2015 20,74 time/year and 2016 is 20,36 time/year. while the standard SAIFI in SPLN 1985 is 3,2 time/year. The result of SAIDI from actual data in 2014 is 16,76 hour/year, 2015 is 30,28 hour/year and 2016 is 35,16 hour/year. while SPLN 1985 standard is 21 hour/year.
\end{abstract}

Key Words : SPLN 1985, SAIDI, SAIFI.

\section{Pendahuluan}

Keandalan energi listrik merupakan salah satu parameter kepuasan masyarakat akan ketersediaan energi listrik. Semakin baik keandalan energi listrik suatu wilayah juga menandakan baiknya penanganan gangguan suatu wilayah. Pada keandalan sistem Indeks yang biasa dipakai adalah Sistem Average Interruption Frequency Index (SAIFI) dan Sistem Average Interruption Duration Index
(SAIDI) ukuran dari nilai keseluruhan keandalan dari sistem [11]. Indeks keandalan yang paling sering digunakan di dunia ini adalah SAIFI, SAIDI dan ENS (Energy Not Supplied) [12]. Nilai SAIDI (System Average Interruption Durration Index ) dan SAIFI (System Average Interruption Frequency Index ) memiliki standar nilai tertentu, SPLN 1985 adalah salah satu standar yang digunakan, sesuai SPLN 1985 standar SAIFI sebesar 3,2 kali/tahun dan SAIDI sebesar $21 \mathrm{jam} / \mathrm{tahun}$ 
[1]. Sudah hampir lebih dari 31 tahun standar yang diterapkan masih sama. Perbedaan teknologi informasi, insfrastruktur jalan, maupun peralatan jaringan listrik antara tahun 1985 dengan tahun 2016 tentunya terdapat perbedaan dan dapat dipertimbangkan sebagai penetapan nilai standar yang baru terhadap terjadinya gangguan agar menciptakan nilai SAIFI (System Average Interruption Frequency Index) atau jumlah padam yang terjadi pada pelanggan selama satu tahun dan juga nilai SAIDI (System Average Interruption Durration Index) atau lama padam pada setiap pelanggan selama satu tahun yang lebih baik.

Pada penelitian ini akan dilakukan perhitungan mengenai angka keluar peralatan di PLN APJ Purwokerto, penghitungan nilai SAIFI (System Average Interruption Frequency Index) atau jumlah padam yang terjadi pada pelanggan serta nilai SAIDI (Sysem Average Interruption Durration Index) atau lama padam pada setiap feeder. Dari perhitungan kemudian dilakukan analisis mengenai relevansi antara perhitungan data yang didapat menggunakan metode SPLN dengan standar ketetapan yang sudah ada di SPLN 1985. Hasil dari perhitungan dan analisis ini adalah nilai angka keluar peralatan, nilai SAIFI setiap rayon serta nilai SAIDI setiap feeder SAIFI adalah jumlah rata-rata gangguan yang dialami pelanggan, secara matematis dapat dirumuskan sebagai berikut :

$f_{2}(\mathrm{x})=\mathrm{SAIFI}=\frac{\sum_{i=1}^{N} \lambda \mathrm{iNi}}{\sum_{i=1}^{N} \mathrm{Ni}}$

Dengan;

$\Lambda \mathrm{i} \quad$ : angka kegagalan rata-rata/frekuensi padam

$\mathrm{Ni}$ : jumlah pelanggan yang dilayani pada titik beban $\mathrm{i}$

Dari rumus di atas, diketahui SAIFI adalah perbandingan jumlah total gangguan dengan total jumlah pelanggang terlayani [13].

SAIDI adalah nilai rata-rata lama waktu padam yang dialami pelanggan, secara matematis dapat dirumuskan sebagai berikut :

$f_{3}(\mathrm{x})=\mathrm{SAIDI}=\frac{\sum_{i=1}^{N} \mathrm{UiNi}}{\sum_{i=1}^{N} \mathrm{Ni}}$

Dengan;

Ui : waktu padam pelanggan dalam periode tertentu (jam/tahun).

$\mathrm{Ni}$ : Jumlah pelanggan yang dilayani pada titik beban i [14].

\section{Metode}

Pada metodologi penelitian akan dijabarkan langkahlangkah yang dilakukan dalam penelitian ini meliputi proses pengumpulan data dan studi literatur, serta perhitungan dan analisis. Pengerjaan penelitian ini dibagi menjadi tiga tahapan, yaitu pra penelitian berupa studi pustaka dan pengumpulan data, baik melalui survei lapangan maupun instansi terkait. Tahapan kedua adalah pengujian data yang diperoleh menggunakan SPSS.
Tahapan ketiga adalah pengolahan data berupa penghitungan angka komponen keluar, SAIDI dan SAIFI serta membandingkan nilai angka komponen keluar SAIDI dan SAIFI data lapangan dengan standar SPLN 1985.

Tahapan pra penelitian ini terdiri dari dua bagian, yaitu studi pustaka untuk mengumpulkan teori dan pengumpulan data. Data yang diperlukan pada penelitian ini adalah data gangguan setiap peralatan yang terjadi di PLN APJ Purwokerto, data jumlah peralatan dan data jumlah pelanggan PLN APJ Purwokerto tahun 2014, 2015 dan 2016.

Pada penelitian kali ini data yang didapatkan dari lapangan dilakukan pengujian terlebih dahulu menggunakan software SPSS untuk mengetahui apakah data bisa digunakan untuk perhitungan atau tidak.

Setelah data tervalidasi kemudian dilakukan perhitungan nilai angka komponen keluar, SAIFI setiap rayon dan nilai SAIDI setiap feeder. Kemudian dilakukan perhitungan nilai SAIDI dan SAIFI berdasarkan standar SPLN 1985 dengan menggunakan metode perhitungan yang terdapat pada SPLN 1985.

Pada hasil akhir akan muncul dua perhitungan yaitu perhitungan berdasarkan data lapangan dan perhitungan berdasarkan standar SPLN 1985. Kedua hasil perhitungan yang didapatkan kemudian dibandingkan untuk mengetahui apakah SPLN 1985 masih layak digunakan atau perlu dikaji kembali. Berikut ini merukan diagram alir dari proses penelitian.

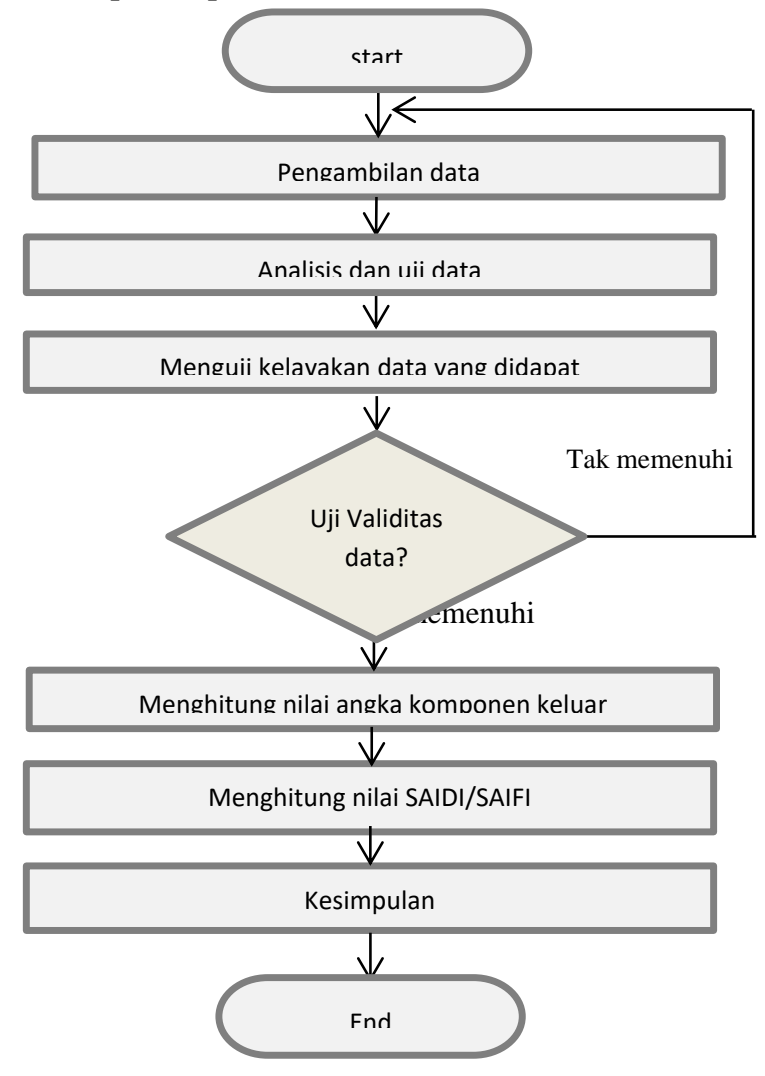

Gambar 1. Diagram alir simulasi sistem kelistrikan 
TRANSIENT, VOL. 7, NO. 1, MARET 2018, ISSN: 2302-9927, 10

\section{Hasil dan Analisa}

Pada bab ini dibahas hasil dari nilai SAIDI dan SAIFI tahun 2014, 2015 dan 2016 dengan standar SPLN 1985.

\section{A. Perbandingan Nilai SAIDI}

Perbandingan nilai SAIDI di tahun 2014, 2015 dan 2016 dilakukan dengan membandingkan nilai SAIDI setiap bulan pada tiga tahun tersebut. Sementara untuk perbandingan nilai SAIDI secara komulatif akan dibahas pada sub bab berikutnya. Berikut ini merupakan tabel perbandingan nilai SAIDI setiap bulan di tahun 2014, 2015 dan 2016.

Tabel 1. Perbandingan Nilai SAIDI setiap bulan di tahun 2014, 2015 dan 2016

\begin{tabular}{ccccc}
\hline \multirow{2}{*}{ NO. } & \multirow{2}{*}{ BULAN } & $\mathbf{3}$ SAIDI (jam/pelanggan) \\
& \multirow{2}{*}{$\mathbf{2 0 1 4}$} & $\mathbf{2 0 1 5}$ & $\mathbf{2 0 1 6}$ \\
\hline 1 & JANUARI & 0,761024 & 2,67322 & 2,90047 \\
2 & PEBRUARI & 0,36115 & 2,75163 & 1,71545 \\
3 & MARET & 0,60096 & 4,78397 & 1,60521 \\
4 & APRIL & 0,48891 & 2,84779 & 1,36249 \\
5 & MEI & 0,26210 & 1,97114 & 2,56102 \\
6 & JUNI & 0,17152 & 1,78293 & 2,65352 \\
7 & JULI & 1,93046 & 1,17841 & 1,95169 \\
8 & AGUSTUS & 0,69047 & 1,53628 & 2,72703 \\
9 & SEPTEMBER & 1,97833 & 1,34378 & 4,02372 \\
10 & OKTOBER & 1,58706 & 2,56069 & 5,47591 \\
11 & NOPEMBER & 4,40992 & 4,61054 & 4,61034 \\
12 & DESEMBER & 3,85696 & 2,84156 & 4,10367 \\
& TOTAL & 16,76247 & 30,28546 & 35,16403 \\
\hline
\end{tabular}

Dari tabel di atas dapat diketahui nilai SAIDI setiap bulan pada tahun 2014, 2015 dan 2016 dan juga nilai SAIDI total di tiga tahun tersebut dimana nilai SAIDI terus mengalami kenaikan dari tahun 2014 sampai 2016. Berikut ini merupakan perbandingan nilai SAIDI setiap bulan di tiga tahun tersebut.

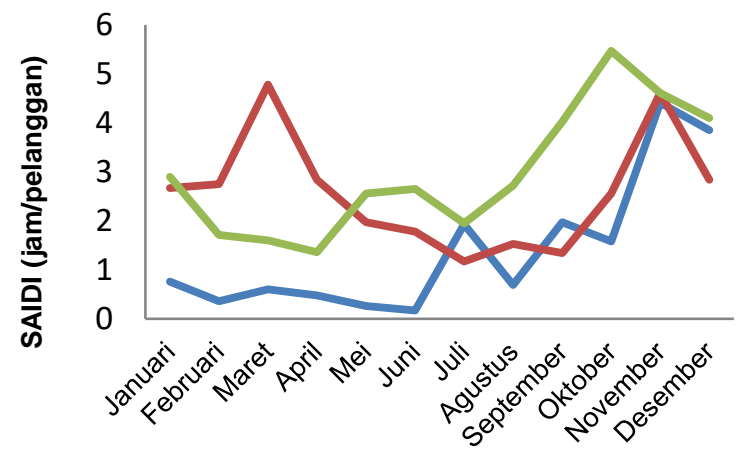

Gambar 2. Grafik perbandingan nilai SAIDI setiap bulan tahun 2014, 2015 dan 2016

Dari grafik di atas diketahui jika nilai SAIDI setiap bulan di tahun 2014, 2015 dan 2016. Pada grafik di atas dapat diketahui nilai SAIDI terbesar di tahun 2014 di bulan November yaitu sebesar 4,61 jam/pelanggan sementara di tahun 2015 nilai SAIDI terbesar pada bulan Maret yaitu
4,78 jam/pelanggan dan di tahun 2016 nilai SAIDI terbesar terjadi di bulan Oktober yaitu 5,74 jam/pelanggan. Berikut ini merupakan tabel perbandingan nilai SAIDI dengan SPLN 1985

Tabel 2. Perbandingan nilai SAIDI tahun 2014, 2015 daan 2016

\begin{tabular}{|c|c|c|c|c|}
\hline Tahun & $\begin{array}{c}\text { Jumlah } \\
\text { Pelanggan }\end{array}$ & $\begin{array}{c}\text { Jam } \\
\text { pelanggan } \\
\text { padam }\end{array}$ & $\begin{array}{c}\text { SAIDI( } \\
\text { Perhitungan) }\end{array}$ & $\begin{array}{c}\text { SAIDI } \\
\text { (SPLN } \\
1985)\end{array}$ \\
\hline 2014 & 954641 & $\begin{array}{c}16002148,4 \\
\text { jam }\end{array}$ & $\begin{array}{c}16,76 \\
\text { jam/tahun }\end{array}$ & $\begin{array}{c}21 \\
\text { jam/tahun }\end{array}$ \\
\hline 2015 & 1010467 & $\begin{array}{c}30526746,6 \\
\text { jam }\end{array}$ & $\begin{array}{c}30,28 \\
\text { jam/tahun }\end{array}$ & $\begin{array}{c}21 \\
\text { jam/tahun }\end{array}$ \\
\hline 2016 & 1050417 & $\begin{array}{c}36936900,6 \\
\text { jam }\end{array}$ & $\begin{array}{c}35,16 \\
\text { jam/tahun }\end{array}$ & $\begin{array}{c}21 \\
\text { jam/tahun }\end{array}$ \\
\hline
\end{tabular}

Dari tabel 2 di atas dapat diketahui total jumlah pelanggan dan jumlah waktu padam setiap pelanggan di tahun 2014, 2015 dan 2016. Dari tabel di atas juga diketahui jika jumlah pelanggan di tahun 2014, 2015 dan 2016 terus meningkat namun juga terjadi peningkatan jam kali pelanggan padam di tahun 2014, 2015 dan 2016, bahkan di tahun 2015 jam kali pelanggan padam naik hampir dua kali lipat dari 16002148,4 jam di tahun 2014 dan 30526746,6 jam di tahun 2015. Hal ini juga memepengaruhi nilai SAIDI yang didapatkan yaitu di tahun 2014 sebesar 16,76 jam/tahun dan di tahun 2015 naik menjadi 30,28 jam/tahun sementara di tahun 2016 nilai SAIDI sebesar 35,16 jam/tahun. Untuk mengetahui perbandingan nilai SAIDI dengan SPLN 1985 di tahun 2014, 2015 dan 2016 berikut ini tabel perbandingannya. Perbandingan nilai SAIDI antara tahun 2014, 2015 dan 2016 dengan standar SPLN 1985 ini bertujuan untuk mengetahui apakah nilai SAIDI di PLN APJ Purwokerto sudah memenuhi SPLN 1985 atau tidak memenuhi serta mengetahui perbandingan nilai SAIDI antara tahun 2014, 2015 dan 2016. Berikut ini merupakan perbandingan nilai SAIDI dengan standar SPLN 1985.

Tabel 3. Perbandingan nili SAIDI tahun 2014, 2015 dan 2016 dengan SPLN 1985

\begin{tabular}{ccc}
\hline Tahun & SAIDI( Perhitungan) & SAIDI (SPLN 1985) \\
\hline 2014 & 16,76 jam/tahun & 21 jam/tahun \\
2015 & 30,28 jam/tahun & 21 jam/tahun \\
2016 & 35,16 jam/tahun & 21 jam/tahun \\
\hline
\end{tabular}

Dari tabel 3 di atas diketahui jika nilai SAIDI PLN APJ Purwokerto tahun 2014 sebesar 16,76 jam/tahun telah memenuhi standar SPLN 1985 sebesar 21 jam/tahun sementara untuk nilai SAIDI di tahun 2015 sebesar 30,28 jam/tahun dan 2016 sebesar 35,16 jam/tahun tidak memenuhi standar SPLN 1985. Berikut ini merupakan grafik perbandingan nilai SAIDI tahun 2014, 2015 dan 2016 dengan SPLN 1985.

Dari diagram pada gambar 3 di atas dapat diketahui perbandingan nilai SAIDI data lapangan dengan SPLN 1985 untuk tahun 2014, 2015 dan 2016. Kotak merah 
pada gambar di atas menunjukan nilai SAIDI standar SPLN 1985 sementara untuk kotak biru menunjukan nilai SAIDI tahun 2014, 2015 dan 2016. Pada gambar di atas diketahui jika hanya nilai SAIDI tahun 2014 sebesar 16,75 jam/tahun yang memenuhi standar SPLN 1985 yaitu sebesar 21 jam/tahun. Sementara untuk nilai SAIDI di tahun 2015 sebesar 30,28 jam/tahun dan tahun 2016 sebesar 35,16 jam/tahun tidak memenuhi standar SPLN 1985.

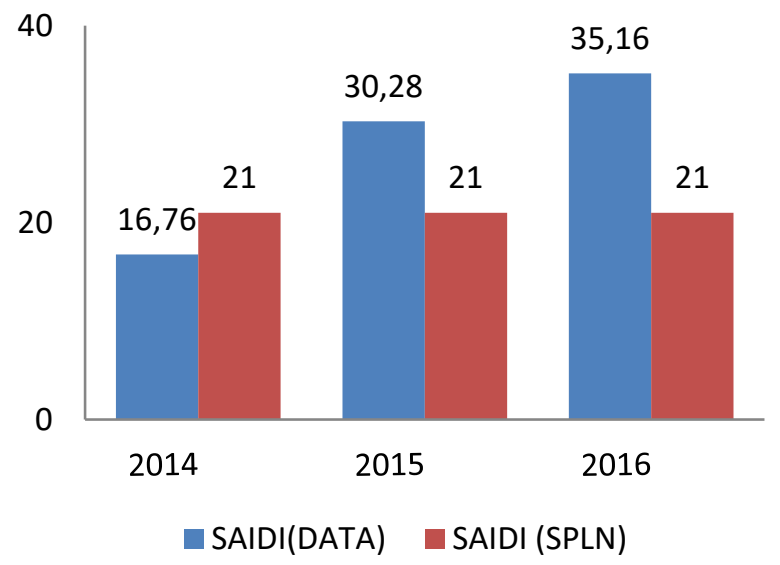

Gambar 3. Diagram perbandingan nilai SAIDI tahun 2014, 2015 dan 2016 dengan SPLN 1985

\section{B. Perbandingan Nilai SAIFI}

Perbandingan nilai SAIFI di tahun 2014, 2015 dan 2016 dilakukan dengan membandingkan nilai SAIFI setiap bulan pada tiga tahun tersebut. Sementara untuk perbandingan nilai SAIFI secara komulatif akan dibahas pada sub bab berikutnya. Berikut ini merupakan tabel perbandingan nilai SAIFI setiap bulan di tahun 2014 , 2015 dan 2016.

Tabel 4. Perbandingan Nilai SAIFI setiap bulan di tahun 2014, 2015 dan 2016

\begin{tabular}{ccccc}
\hline \multirow{2}{*}{ NO. } & \multirow{2}{*}{ BULAN } & 2014 & 2015 & 2016 \\
\hline 1 & JANUARI & 0,85290 & 1,84700 & 2,15797 \\
2 & PEBRUARI & 0,36523 & 1,66408 & 1,33700 \\
3 & MARET & 0,85108 & 2,70440 & 1,10614 \\
5 & MEI & 0,26760 & 1,55379 & 1,39402 \\
6 & JUNI & 0,19289 & 1,31950 & 1,38193 \\
7 & JULI & 0,85874 & 0,84113 & 1,54558 \\
8 & AGUSTUS & 0,43546 & 1,01659 & 1,48658 \\
9 & SEPTEMBER & 1,10255 & 1,17946 & 2,13143 \\
10 & OKTOBER & 0,93067 & 1,81537 & 2,65665 \\
11 & NOPEMBER & 2,88030 & 3,05604 & 2,211347 \\
12 & DESEMBER & 2,48500 & 2,15792 & 2,124561 \\
& TOTAL & 11,69943 & 21,19321 & 20,70463 \\
\hline
\end{tabular}

Dari tabel di atas dapat diketahui nilai SAIFI setiap bulan pada tahun 2014, 2015 dan 2016 dan juga nilai SAIFI total di tiga tahun tersebut dimana nilai SAIFI terus mengalami kenaikan dari tahun 2014 sampai 2016. Berikut ini merupakan perbandingan nilai SAIFI setiap bulan di tiga tahun tersebut.

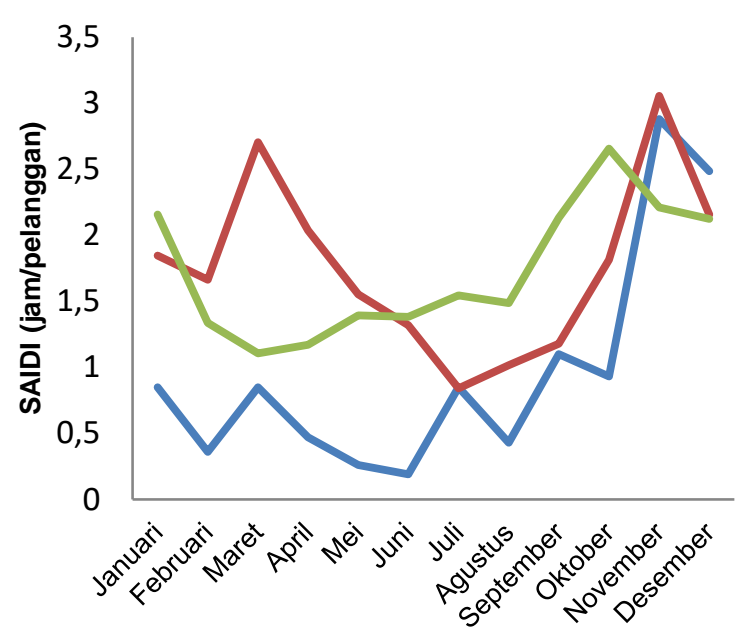

Gambar 4. Grafik perbandingan nilai SAIFI setiap bulan tahun 2014, 2015 dan 2016

Dari grafik di atas diketahui jika nilai SAIFI setiap bulan di tahun 2014, 2015 dan 2016. Pada grafik di atas dapat diketahui nilai SAIFI terbesar di tiga tahun tersebut terjadi di tiga bulan terakhir, pada tahun 2014 nilai SAIFI terbesar terjadi di bulan November yaitu sebesar 2,88 kali/pelanggan sementara di tahun 2015 nilai SAIFI terbesar pada bulan November yaitu 3,06 kali/pelanggan dan di tahun 2016 nilai SAIFI terbesar terjadi di bulan Oktober yaitu 2,66 kali/pelanggan. Kemudian untuk mengatahui perbandingan nilai SAIDI di PLN APJ Purwokerto di tahun 2014, 2015 dan 2016 dengan SPLN 1985 akan diberikan tabel dan grafik perbandingan untuk nilai SAIFI data dengan SPLN 1985. Perbandingan nilai SAIFI antara tahun 2014, 2015 dan 2016 dengan standar SPLN 1985 ini bertujuan untuk mengetahui apakah nilai SAIFI di PLN APJ Purwokerto sudah memenuhi SPLN 1985 atau tidak memenuhi serta mengetahui perbandingan nilai SAIFI antara tahun 2014, 2015 dan 2016. Berikut ini merupakan perbandingan nilai SAIFI dengan standar SPLN 1985.

Tabel 5. Perbandingan nili SAIFI tahun 2014, 2015 dan 2016 dengan SPLN 1985

\begin{tabular}{ccc}
\hline Tahun & SAIFI( Perhitungan) & SAIFI (SPLN 1985) \\
\hline 2014 & 11,44 kali/tahun & 3,2 kali/tahun \\
2015 & 20,74 kali/tahun & 3,2 kali/tahun \\
2016 & 20,36 kali/tahun & 3,2 kali/tahun \\
\hline
\end{tabular}

Dari tabel 5 di atas diketahui jika nilai SAIFI PLN APJ Purwokerto tahun 2014 sebesar 11,44 kali/tahun, sementara untuk nilai SAIFI di tahun 2015 sebesar 20,74 kali/tahun dan 2016 sebesar 20,36 kali/tahun tidak memenuhi standar SPLN 1985 yaitu sebesar 3,2 kali/tahun. Dari ketiga nilai SAIFI di tiga tahun tersebut dapat diketaqhui jika nilai SAIFI pada tahun 2014, 2015 dan 2016 di PLN APJ Purwokerto tidak memenuhi Standar SPLN 1985. Berikut ini merupakan grafik 
perbandingan nilai SAIFI tahun 2014, 2015 dan 2016 dengan SPLN 1985

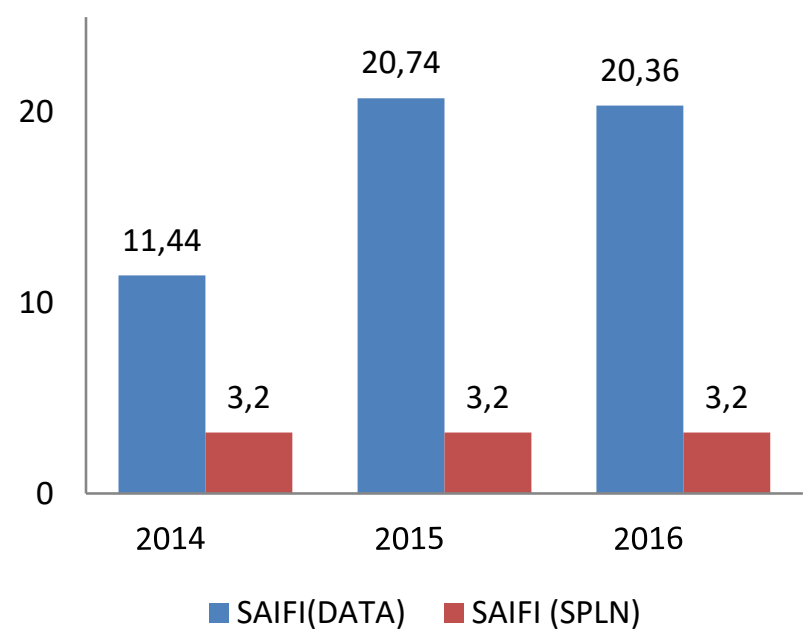

Gambar 5. Diagram perbandingan nilai SAIFI tahun 2014, 2015 dan 2016

Dari diagram pada gambar di atas dapat diketahui perbandingan nilai SAIFI data lapangan dengan SPLN 1985 untuk tahun 2014, 2015 dan 2016. Garis merah pada gambar di atas menunjukan nilai SAIFI standar SPLN 1985 sementara untuk garis biru menunjukan nilai SAIFI tahun 2014, 2015 dan 2016. Pada gambar di atas diketahui jika nilai SAIFI tahun 2014 sebesar 11,44 kali/tahun, tahun 2015 sebesar 20,74 kali/tahun dan tahun 2016 sebesar 20,36 kali/tahun tidak memenuhi standar SPLN 1985 tidak memenuhi standar SPLN 1985 yaitu sebesar 3,2 kali/tahun.

\section{Kesimpulan}

Berdasarkan pada penelitian, perhitungan dan analisa yang telah dilakukan diperoleh nilai SAIFI tahun 2014 sebesar 11,47 kali/tahun, tahun 2015 sebesar 20,74 kali/tahun dan 2016 sebesar 20,36 kali/tahun sementara standar SAIFI SPLN sebesar 3,2 kali/tahun.. Nilai SAIDI data lapangan tahun 2014 sebesar 16,76 jam/tahun, tahun 2015 sebesar 30,28 jam/tahun dan tahun 2016 sebesar 35,16 jam/tahun sementara standar SPLN sebesar 21 jam/tahun. Nilai SAIFI PLN APJ Purwokerto tahun 2014, 2015 dan 2016 tidak ada satupun yang memenuhi standar SPLN 1985. Sementara, untuk nilai SAIDI di PLN APJ Purwokerto pada tahun 2014 dapat memenuhi standar
SPLN 1985 namun untuk tahun 2015 dan 2016 tidak memenuhi standar SPLN 1985.

Tidak terpenuhinya nilai SAIDI ataupun SAIFI yang terjadi di PLN APJ Purwokerto dikarenakan jumlah pemadaman dan pelanggan padam jauh lebih banyak daripada jumlah pelanggan sementara untuk durasi padamnya juga terlalu lama.

\section{Referensi}

[1]. SPLN 59 Keandalan Pada Sistem Distribusi 20 kV dan 6 $k V$, SPLN 1985, 1985.

[2]. $\quad$ Tentang Pedoman Pelayanan Teknik Direktorat Operasi Jawa-Bali, SK DIR No. 210. K/DIR/2012, 2012

[3]. W. Breuer, D. Retzmann, K. Uecker, "Highly Efficient Solutions for Smart and Bulk Power Transmission of "Green Energy'”, Jerman, 2010, hal. 4

[4]. R.E Brown, Electric Power Distribution Reliability, Marsel Dekker, Inc, New York, 2002.

[5]. R.E Brown, "analitycal and empirical techniques" ,dalam , Electric Power Distribution Reliability, IEEE Power EngineeringSociety General Meeting, 2005.

[6]. N. Balijepalli , S.S Venkata, R.D. Christie, "Modeling and analysis of distribution reliability indices", IEEE Trans. Power Deliv, 19 (4 Oktober). 2004

[7]. R.E Brown, Electric Power Distribution Reliability, $2^{\text {nd }}$ ed, Boca Raton, CRC Press, 2009

[8]. R. Billinton, R.N. Allan, "Reliability Evaluation of Power Systems", $2^{\text {nd }}$ edn, Plenum Press, New York, 1996

[9]. Ir. Sulasno, "Keandalan Sistem Distribusi," dalam Teknik dan system Distribusi Tenaga Listrik, Badan Penerbit Universitas Diponegoro, Semarang, 2001, hal. 129-132.

[10]. IEEE Trial-Use Guide For Electrical Power Distribution Reliability Indices. IEEE Standard. 1998

[11]. J. Chan, S. Chang, "A neural network approach to evaluate distribution system reliability", Syst, Inggris, 1992

[12]. IEEE Guide for electric power distribution reliability indices . IEEE standard, 2004, hal. 1366-2012

[13]. A. Kavousifard, H. Samet, "consideration effect of uncertainty in power system reliability indices using radial basis function network and fuzzy logic theory", Neurocomputing 74, 2011, hal. 3420-3427

[14]. A.H. Etemadi, M. Fotuhi-Firuzabad, "Distribution system reliability enhancement using optimal capasitor placement", 2008, hal. 621-631

[15]. A S Pabla, " Sistem Keterandalan," dalam Electrical Power Distribution, TATA McGraw-Hill, New Delhi, India, 2008, hal.112-114 